\title{
Synthesis, and Spectral Studies of Demi-macrocycles of Ligand N2O2 with Ni (II) and Cu (II) Ions
}

\author{
Sameena Rasheed ${ }^{1 *}$, Arvind Prasad Dwivedi ${ }^{2}$,M. U. Khan ${ }^{1}$ \\ ${ }^{1}$ Department of Chemistry, Govt. Girls P.G. College (NAAC) Rewa (M.P.) India. \\ ${ }^{2}$ Department of chemistry, Govt. Sanjay Gandhi Smrati Auto., P.G., College Sidhi M.P India
}

*Corresponding Author: Sameena Rasheed, Department of Chemistry, Govt. Girls P.G. College (NAAC) Rewa (M.P.) India.

\begin{abstract}
The new series of demi-macrocycles of the type [ $\mathrm{C}_{14} \mathrm{H}_{30} \mathrm{~N}_{2} \mathrm{O}_{2}\left(\mathrm{Cl}_{2} \mathrm{O}_{4}\right)_{2}$ ] having $\mathrm{N}_{2} \mathrm{O}_{2}$ as donors ligand were synthesized by the equimolar condensation reaction of ethane-1,2-diamine in acetone in presenced of perchloric acid. The head unit of demi-macrocycle formed was proposed by the two acetone molecules [M $\left.\left(\mathrm{C}_{14} \mathrm{H}_{30} \mathrm{~N}_{2} \mathrm{O}_{2}\right)\left(\mathrm{ClO}_{4}\right)_{2}\right]$ Where, $\mathrm{M}=\mathrm{Ni}(\mathrm{II})$ and $\mathrm{Cu}(\mathrm{II})$ were formed by the reaction ofproposed demi-macrocycle with respective metal salts. The complexes formed were characterized by the elemental analysis, conductance and magnetic susceptibilities measurements, and also by spectral methods.
\end{abstract}

Keywords: Attributed, implications incur, quest, relaxation.

\section{INTRODUCTION}

Macrocyclic ligands are considerably attractive in the quest for new chemistry, because they offer a wide variety of donor atoms, ionic charges, coordination numbers and geometry of the resultant complexes..$^{[1-5]}$. During recent years macrocyclic chemistry has attracted much more attention, so it has become a growing class of research. The structure of mono-nucleating aza-macrocycle is a organic framework which holds a transition metal ion via a nitrogen atoms, with varying substuients on the carbon atoms. Macrocycles or demi-macrocyclic ligands are polydentate ligand containing their donor atoms either incorporated in or less commonly attached to a cyclic backbone.

The understanding of the metal ion chemistry of macrocyclic ligands has important implications for a range of chemical and biochemical applications. ${ }^{[6,7]}$. Macrocyclic ligand complexes are of great importance in enhancing various industrial applications and in a number of biological processes such as photosynthesis and di-oxygen transport. ${ }^{[8]} \mathrm{Cu}(\mathrm{II})$ is the most studied metal ions $\mathrm{s}^{[9,10]}$ playing significant role either in naturally occurring biological systems or as pharmological agents. ${ }^{[11,12,13]}$ Here we report the synthesis of demi-macrocyclic complexes of ethylene diamine and acetone with $\mathrm{Ni}(\mathrm{II})$ and $\mathrm{Cu}(\mathrm{II})$.

\section{MATERIALS AND METHODS}

All reagents and solvents used in the present investigation were of standard grade. 1,2 diaminoethane, perchloric acid $\left(\mathrm{HCIO}_{4}\right)$, acetone $\left(\mathrm{CH}_{3} \mathrm{COCH}_{3}\right)$ of Loba, Merck and Aldrich brands. The preparation of solutions, standardization, and procedures for demi-macrocyclic complex formation and their spectral kinetic studies have been performed.

The carbon, hydrogen and nitrogen analysis of the samples were carried out microanalytically. Oxygen was determined by different methods. Metal and chloride were determined gravimetrically. The IR spectra (4000-400 $\mathrm{cm}^{-1}$ ) were recorded on a Jasco model 4100 FTIR spectrometer as KBr discs. UV visible spectra were recorded on a shimedzu 1700 pharmaspectrometer. Conductivity measurements were made in DMSO or nitromethane $\left(10^{-3} \mathrm{mho}\right)$ at room temperature on systronics conductivitymeter. Magnetic susceptibility was measured at $8000 \mathrm{G}$ in a Evans magnetic susceptibility balance using $\mathrm{Co}\left[\left(\mathrm{Hg}(\mathrm{SCN})_{4}\right)\right]$ as calibrant and the experimental susceptibilities were corrected for diamagnetic correction with pascal constants. ${ }^{[14-16]}$ 


\subsection{Synthesis of Ligand}

4,4,9,9-tetramethyl-5,8-diazoniumdiodeca-2,11-dione diperchlorate

Ethane-1,2-diamine (33.83) $\mathrm{ml}$ was added to acetone(36.80) $\mathrm{ml}$ in $5000 \mathrm{ml}$ flask and solution was cooled in a icebath, perchloric acid was added drop wise with stirring and keeping the temperature below $5^{\circ} \mathrm{C}$, the flask was completely filled with acetone and left without agitation under freezing conditions. After two days fine crystals of the product, which is insoluble in acetone, commenced to separate. The bulk of the product being present after two days was filtered off, washed with acetone until brown color vanished and the product remained was colorless and was air dried. The yield was equal to $85 \%$ (Table 1 ).

Table1. $\mathrm{C}_{14} \mathrm{H}_{30} \mathrm{~N}_{2} \mathrm{O}_{10} \mathrm{Cl}_{2} 457.30$ Calcd. Mass (M)

\begin{tabular}{|l|l|}
\hline \% Calculated Mass & \% Observed Mass \\
\hline $\mathrm{C}=36.77$ & $\mathrm{C}=36.24$ \\
\hline $\mathrm{H}=6.61$ & $\mathrm{H}=6.59$ \\
\hline $\mathrm{N}=6.12$ & $\mathrm{~N}=6.15$ \\
\hline $\mathrm{O}=34.98$ & $\mathrm{O}=34.92$ \\
\hline $\mathrm{Cl}=15.50$ & $\mathrm{Cl}=15.49$ \\
\hline
\end{tabular}

\section{IR Spectral data of Ligand}

$I R(\mathrm{KBr}) v_{a s}(\mathrm{C}-\mathrm{H}) 2960(\mathrm{M}), v_{s}(\mathrm{C}-\mathrm{H}) 2909 \mathrm{~cm}^{-1}, v\left(-\mathrm{C}-\left(\mathrm{CH}_{3}\right)_{2}\right) 1385,1565(\mathrm{~s})$

$\boldsymbol{V}(\mathrm{C}=\mathrm{O}) 1685(\mathrm{~s}), \mathrm{v}(\mathrm{N}-\mathrm{H}) 3370, \boldsymbol{v}(\mathrm{N}-\mathrm{C}) 1260$,

$v_{a s}\left(\mathrm{CH}_{2}\right) 2985, v_{s}\left(\mathrm{CH}_{2}\right) 3007, \delta_{S}\left(\mathrm{CH}_{3}\right) 1348 \mathrm{~cm}^{1}, \delta_{a s}\left(\mathrm{CH}_{3}\right) 1445 \mathrm{~cm}^{-1}$

$\delta_{S}\left(\mathrm{CH}_{2}\right) 1473 \mathrm{~cm}^{-1} v\left(\mathrm{CIO}_{4^{-}}\right) 1105,655 \mathrm{~cm}^{-1}$

\subsection{Syntheses of Demi-Macrocyclic Complexes}

\section{a) Synthesis of Ni(II) Complex}

4,4,9,9-Tetramethyl-5,8- diazadodeca-2,11-dione Nickel (II) complex

Nickel (II) sulphate hexahydrate (1.31gms) was dissolved in water $(18 \mathrm{ml})$ followed by respective ligand (4.57gms). The mixture was stirred until the liquid dissolved, the colour of the solution gradually changed from blue to red and the orange product crystallized. After several hours the solution was cooled in ice and the product was filtered off and washed with ice cold water yield (3gms, 80\%) recrystallised from hot 1:1 water methanol or from hot acetonitrile /propanol-2, the compound was also formed by reacting respective ligand with nickel acetate tetrahydratpin methanol (Table 2).

Table2. $\mathrm{C}_{14} \mathrm{H}_{28} \mathrm{~N}_{2} \mathrm{O}_{10} \mathrm{Cl}_{\mathrm{Ni}} 513.994$ Calcd. Mass (M)

\begin{tabular}{|c|c|}
\hline \% Calculated Mass & \% Observed Mass \\
\hline $\mathrm{C}=32.71$ & $\mathrm{C}=32.72$ \\
\hline $\mathrm{H}=5.49$ & $\mathrm{H}=5.47$ \\
\hline $\mathrm{N}=5.45$ & $\mathrm{~N}=5.43$ \\
\hline $\mathrm{O}=31.12$ & $0=31.11$ \\
\hline $\mathrm{Cl}=13.79$ & $\mathrm{Cl}=13.78$ \\
\hline $\mathrm{Ni}=11.42$ & $\mathrm{Ni}=11.4$ \\
\hline
\end{tabular}

\section{IR (KBr)}

$v\left(\mathrm{ClO}_{4^{-}}\right) 1100 \mathrm{~s}, 620 \mathrm{~s}$

$v(\mathrm{Ni}-\mathrm{O}) 470 \mathrm{~cm}^{-1}, v(\mathrm{Ni}-\mathrm{N}) 405 \mathrm{~cm}^{-1}$

(d-d) Spectra (methanol) $\mathrm{cm}^{-1} \quad 8140{ }^{3} \mathrm{~A}_{2}(\mathrm{~F}) \rightarrow{ }^{3} \mathrm{~T}_{2}(\mathrm{~F})$

$13477{ }^{3} \mathrm{~A}_{2}(\mathrm{~F}) \rightarrow{ }^{3} \mathrm{~T}_{1}(\mathrm{~F})$

$$
\begin{aligned}
24000{ }^{3} \mathrm{~A}_{2}(\mathrm{~F}) & \rightarrow{ }^{3} \mathrm{~T}_{2}(\mathrm{~F}) \\
35350 & \rightarrow \mathrm{CT}
\end{aligned}
$$

$\mathrm{Dq}=820, \mathrm{~B}=873, \beta=839$

$\mu_{\mathrm{eH}}=3.51 \mathrm{BM}$ 


\section{b) Synthesis of Demi-Macro-Cyclic Complex of $\mathbf{C u}(\mathrm{II})$}

\section{4,4, 9, 9-Tetramethyl - 5, 8-diazadodeca-2,11-dione copper (II) complex}

Copper (II) sulphate $(1.29 \mathrm{gms})$ was dissolved in water $(36 \mathrm{ml})$ followed by the ligand $(4.57 \mathrm{gms})$. The mixture was refluxed until the ligand dissolved. The color of the solution changed gradually from fast blue to light blue and black colored product crystallized. After several hours the solution was cooled in ice bath and the product was filtered off and washed with ice coldwater, yield (3gms, $76 \%)$ recrystallised from 1:1 hot water methanol or from hot acetonitrile propanol-2.The compound was also formed by reacting the respective ligand with copper acetate tetrahydrate in methanol (Table 3).

Table3. $\mathrm{C}_{14} \mathrm{H}_{28} \mathrm{~N}_{2} \mathrm{O}_{10} \mathrm{Cl}_{2} \mathrm{Cu}, 524.55 \mathrm{Calcd}$. Mass (M)

\begin{tabular}{|l|l|}
\hline$\%$ Calculated Mass & \% Observed Mass \\
\hline $\mathrm{C}=32.33$ & $\mathrm{C}=32.34$ \\
\hline $\mathrm{H}=5.33$ & $\mathrm{H}=5.29$ \\
\hline $\mathrm{N}=5.27$ & $\mathrm{~N}=5.30$ \\
\hline $\mathrm{O}=31.05$ & $\mathrm{O}=31.10$ \\
\hline $\mathrm{Cl}=13.50$ & $\mathrm{Cl}=13.54$ \\
\hline $\mathrm{Cu}=11.19$ & $\mathrm{Cu}=11.24$ \\
\hline
\end{tabular}

\section{IR (KBr)}

$$
\begin{gathered}
v(\mathrm{Cu}-\mathrm{N}) 522 \mathrm{~cm}^{-1}, v(\mathrm{Cu}-\mathrm{O}) 495 \mathrm{~cm}^{-1} \\
\text { d-d spectra (DMSO) } 10810 \mathrm{E}^{2} \rightarrow{ }^{2} \mathrm{~T}_{2} \quad \mathrm{Dq}=1081 \\
35010 \rightarrow \mathrm{CT}
\end{gathered}
$$

$$
=2.08 \mathrm{BM}
$$

Conductivity $\mathrm{ohm}^{-1} \mathrm{~cm}^{2} \mathrm{~mol}^{-1}=13.0$

\section{RESULTS AND DISCUSSION}

\subsection{Characte rization of the Ligand}

The 14-membered $\mathrm{N}_{2} \mathrm{O}_{2}$ demi-macrocycle has been synthesized by mixed condensation of ethane-1,2diamine with acetone as per the standard method. The addition of acids activates the amine group by protonation. The analytical results of the ligand and complexes are in conformity with their proposed compositions.

\subsection{IR Spectra of $\mathrm{N}_{2} \mathrm{O}_{2}$}

The IR Spectra of the ligand shows characteristic strong absorption band at $2960 \mathrm{~cm}^{1}$ primarily due the asymmetric stretching mode in which the two $\mathrm{C}-\mathrm{H}$ bonds of the methyl group are extending while the third one is contracting and at $2904 \mathrm{~cm}^{1}$ due to symmetrical stretching (vsGHb) in which all three of the $\mathrm{C}-\mathrm{H}$ bond extend and contract in phase. The peak at $2985 \mathrm{~cm}^{1}$ and 3007 are attributed to the asymmetrical stretching $\left(\mathrm{v}_{\mathrm{as}} \mathrm{CH}_{2}\right)$ and symmetrical stretching $\left(\mathrm{v}_{\mathrm{s}} \mathrm{CH}_{2}\right)$. The high energy shifting of these peaks reflect strain in the chain. The symmetrical bending vibration $\left(5_{\mathrm{s}} \mathrm{CH}_{3}\right)$ causes peak at $1348 \mathrm{~cm}-{ }^{1}$, while the sharp peak at $1445 \mathrm{~cm}^{-1}$ is attributed to asymmetrical bending $\left(5_{\mathrm{as}} \mathrm{CH}_{3}\right)$. Strong absorption band at $1473 \mathrm{~cm}^{1}$ is the sciccoring band $\left(5_{\mathrm{s}} \mathrm{CH}_{2}\right)$ of methylene group. Absorption band between 1313 $\mathrm{cm}^{1}$ to $1156 \mathrm{~cm}^{1}$ is ascribed to twisting and wagging vibrations of methylene group. Strong absorption peak at $1685 \mathrm{~cm}^{1}$ is due to ketonic stretching vibration. Overlapping band peak at 3019, 3007, 3266 and 33701 are due to the $\mathrm{N}-\mathrm{H}$ stretching vibration. Strong bands due to ionic perchlorate occur at 1105 $\mathrm{cm}^{-1}$ and $655 \mathrm{~cm}^{-1}$ (Fig. 1).

\subsection{Characte rization of Complexes}

The metal complexes have been synthesized by the reaction of the respective metal perchlorates with the demi-macrocyclic ligand according to the following reaction.

$$
\begin{aligned}
& \mathrm{M}\left(\mathrm{ClO}_{4}\right)_{2}+\mathrm{L} \rightarrow \mathrm{ML}\left(\mathrm{ClO}_{4}\right)_{2} \\
& \text { Where, } \mathrm{M}=\mathrm{Ni}(\mathrm{II}), \mathrm{Cu}(\mathrm{II})
\end{aligned}
$$

The molar conductance values $\left(\lambda \mathrm{m}=5-15 \Omega^{-1} \mathrm{~cm}^{2} \mathrm{~mol}^{1}\right)$ of the complexes in DMSO $\left(10^{-3} \mathrm{M}\right)$ indicate their non-electrolytic nature. 


\subsection{IR Spectra}

The IR spectra of the complexes exhibit a strong sharp to medium intensity band at $500-457 \mathrm{~cm}^{-1}$ region which may be assigned to metal oxygen stretching vibration. The $\mathrm{v}(\mathrm{M}-\mathrm{O})$ stretching frequency are in order of $\mathrm{Cu}>\mathrm{Ni}$. Upon complex formation the intensities of some the vibrations are decreased which may be attributed to the hindered vibrations.

The characteristic $\mathrm{v}(\mathrm{C}-\mathrm{O})$ absorption frequencies undergo a negative shift by about $50 \mathrm{~cm}^{-1}$ in the complexes which may be ascribed to the relaxation effect caused to the lone pair donation by the oxygen atom to the metal ion. The $\mathrm{v}\left(\mathrm{M}-\mathrm{C}_{10} \mathrm{O}_{4}\right)$ stretching frequency sharp band at $535-500 \mathrm{~cm}^{-1}$ is assigned to the metal-nitrogen stretching frequency. The order of $\mathrm{v}(\mathrm{M}-\mathrm{N})$ stretching frequencies is $\mathrm{Cu}>\mathrm{Ni}$. The non-appearance of $\mathrm{v}_{\mathrm{s}}(\mathrm{N}-\mathrm{H}), \mathrm{v}_{\mathrm{a}} \mathrm{s}(\mathrm{N}-\mathrm{H})$ and $8(\mathrm{~N}-\mathrm{H})$ vibrations in the complexes confirm the coordination of the metal ion by the deprotonation of the internal protons.

\subsection{UV-Visible Spectra}

The electronic spectra of the complexes was recorded in various solvents. The electronic spectral data of the complexes indicate an octahedral geometry around tire metal ion.

The electronic spectra of the copper complex shows a band at $10,869-10,752 \mathrm{~cm}^{1}$ corresponding to ${ }^{2} \mathrm{E}$ $\rightarrow{ }^{2} \mathrm{~T}_{2}$ transition, which is characteristic of the octahedral $\mathrm{Cu}$ (II) complex.

The Ni(II) complex exhibits three absorption bands at 8, 200-8,140, 13,531-13,477 and 24,096-24,000 $\mathrm{cm}^{1}$ which can be attributed to the three allowed d-d transitions arising from ${ }^{2} \mathrm{~A}_{2}(\mathrm{~F})$ ground state to ${ }^{3} \mathrm{~T}_{2}(\mathrm{~F})(\mathrm{vi}),{ }^{3} \mathrm{~T}_{2}(\mathrm{~F})\left(\mathrm{v}_{2}\right)$, and ${ }^{3} \mathrm{~T}_{2}(\mathrm{~F})\left(\mathrm{v}_{3}\right)$ excited states respectively indicating an octahedral environment around $\mathrm{Ni}$ (II).These assignments are further supported by a close agreement between the observed and calculated values of Amax for the $\mathrm{v}_{2}$ transition and also by the constant value of the intensity ratio of ${ }^{3} \mathrm{~A}_{2}(\mathrm{~F}){ }^{3} \mathrm{Ti}(\mathrm{P})$ to ${ }^{3} \mathrm{~A}_{2}(\mathrm{~F}){ }^{3} \mathrm{~T}_{2}(\mathrm{~F})$ transitions.

The observed magnetic moment of $2.08 \mathrm{BM}$ of copper complex are higher than the expected values, probably due to octahedral geometry around $\mathrm{Cu}(\mathrm{II})$ ion.

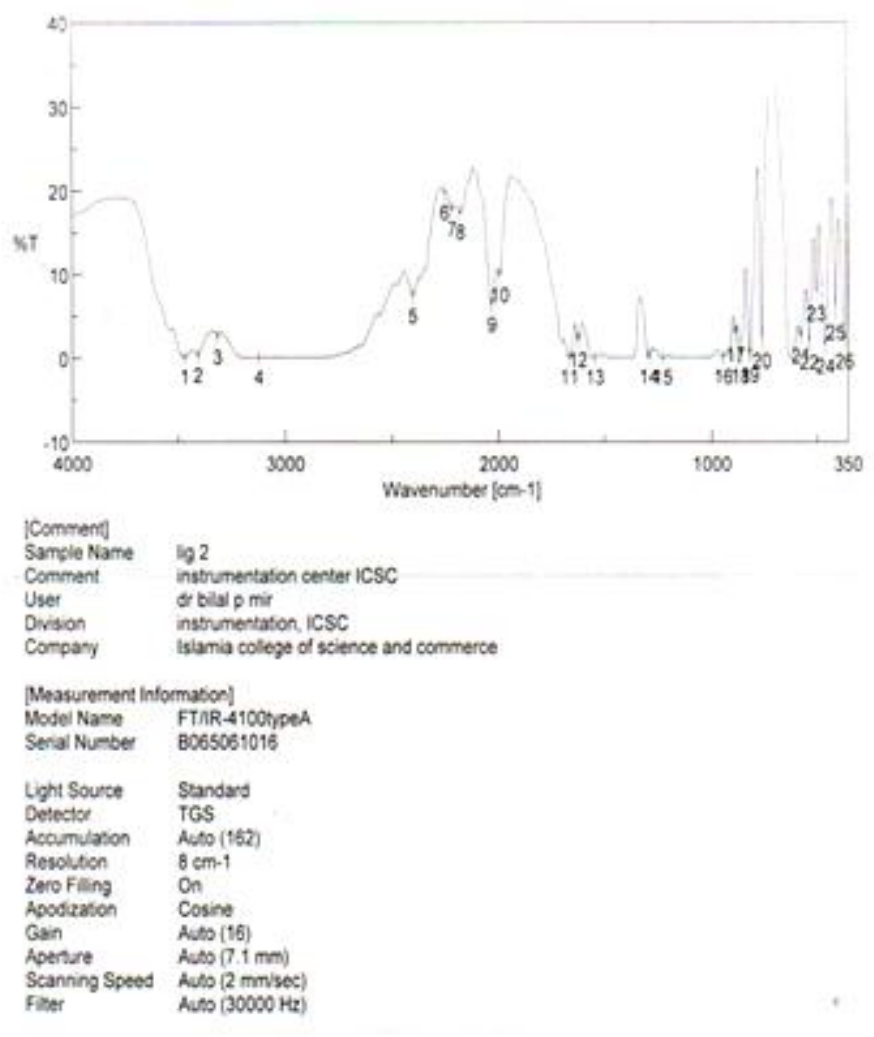

Fig1. IR Spectra of $2 \mathrm{O} 2$

\section{CONCLUSion}

Synthesis and spectral studies of demi-macrocycles of ligand $\mathrm{N}_{2} \mathrm{O}_{2}$ with $\mathrm{Ni}(\mathrm{II})$ and $\mathrm{Cu}(\mathrm{II})$ ions are characterized by the elemental analysis. Conductance measurements and IR spectral methods show important implicationos for a range of chemical and bio-chemical applications as well as in biological processes. 


\section{REFERENCES}

[1] Reddy, P.M.; Prasad, A.V.S.S.; Rohini, R.; Ravinder, V.: Catalytic reduction of pralidoxime in pharmaceuticals by macrocyclic Ni (II) compounds derived from rthophthalaldehyde. Spectrochim. Acta a 2008, 70, 704-712.

[2] Reddy, P.M.; Prasad, A.V.S.S.; Shanker, K.; Ravinder, V: Synthesis, spectral studies and antibacterial activity of novel macrocyclic Co (II) compounds. Spectrochim. Acta a 2007, 68, 1000-1006.

[3] Lim, I.T.; Choi, K.Y: One-dimensional hydrogen-bonded infinite chain from Ni (II) tetraaza macrocyclic complex and 1, 2-cyclopentanedicarboxylate ligand. Int. J. Mol. Sci., 2011, 12, 2232-2241.

[4] Reddy, P.M.; Ho, Y.P.; Shanker, K.; Rohini, R.; Ravinder,V. Physiochemical and biological characterization of novel macrocycles derived from o-phthalaldehyde. Eur. J. Med. Chem., 2009, 44, 2621-2625.

[5] Borisova, N.E.; Reshetova, M.D.; Ustynyuk, Y.A. Metal-free methods in the synthes is of macrocyclic Schiff bases. Chem. Rev. 2006, 107, 46-79.

[6] Ma, W.; Tian, Y.P.; Zhang, S.Y.; Wu, J.-Y; Fun, H.-K.; Chantrapromma, S. Synthesis and characterization of 1-8-bis (ferrocenylmethyl)-5,5,12,12,14-hexamethyl-1,4,8,1 tetrazacyclotetradecane, a macrocyclic ligand and its complexes. Transition Met. Chem., 2006, 31, 97-102.

[7] Martin, E.M.; Bereman, R.D.; Singh, P. X-ray crystallographic studies of Ni (II) complexes of tetradentate $\left[\mathrm{N}_{2} \mathrm{~S}_{2}\right]$ 2-ligands. 3, Astepwise distortion from square-planar to pseudo- tetrahedral geometries. Inorg. Chem. 1991, 30,957-962.

[8] Chandra, S.; Gupta, K. Chromium (III), manganese (II), iron (III), cobalt (II), nickel (II) and copper (II) complexes with pentadentate, 15-membered new macrocyclic ligand. Transition. Met. Chem. 2002, 27,196199.

[9] Ajibade, P.A.; Zulu, N.H. Metal complexes of diisopropylthiourea: Synthesis, characterization and antibacterial studies. Int. J. Mol. Sci. 2011, 12, 7186-7198.

[10] Reddy, P.M.; Prasad, A.V.S.S.; Ravinder, V. Synthesis, spectral characterization,* catalytic and antibacterial activity of macrocyclic Cu (II) compounds. Transit. Met. Chem. 2007, 32, 507-513.

[11] Budgie, G.; Puchakayala, M.R.; Kongara, S.R.; Hu, A.; Vadde, R. Synthesis, characterization and biological evaluation of mononuclear $\mathrm{Co}(\mathrm{II}), \mathrm{Ni}(\mathrm{II}), \mathrm{Cu}$ (II) and $\mathrm{Pd}(\mathrm{II})$ complexes with new $\mathrm{N}_{2} \mathrm{O}_{2}$ schiff base ligands. Chem. Pharm. Bull. 2011,59,166-171.

[12] Chandra, S.; Jain, D.; Sharma, P. Coordination modes of a Schiff base pentadentate derivative of 4aminoantipyrine with cobalt (II), nickel (II) and copper (II) metal ions: Synthesis, spectroscopic and antimicrobial studies, Molecules, 2009, 14,174-190.

[13] P.W. Selwood, "Magnetochemistry", Inter science.2nd ed. (1956); R.L Carlin and A.J.V. Duyhevldt. Magnetic properties of transition metal compounds, Springer-Verlo, New York, 1977.

[14] Figgs, B.N., and Lewis, J: "Modern coordination chemistry." (Eds) J.Lewis and R.G. Williams, Inter science, New York, 1960.

[15] Rasheed, Sameena, Khan, M.U. and Swami, M.N: Int. J. Chem. Sci. Secrets, 2015, No.1, Vol., 54-75.

[16] Rasheed, Sameena, Khan, M.U. and Parihar, S.S: Ele. J. Adv. Research, 2017, Vol. 3(2), 102, 110.

Citation: S. Rasheed et al., "Synthesis, and Spectral Studies ofDemi-macrocycles of Ligand N2O2 with Ni(II) and Cu (II) Ions", International Journal ofAdvanced Research in Chemical Science (IJARCS), vol. 5, no. 2, pp. 15-19, 2018. http://dx.doi.org/10.20431/2349-0403.0503003

Copyright: (c) 2018 Authors. This is an open-access article distributed under the terms of the Creative Commons Attribution License, which permits unrestricted use, distribution, and reproduction in any medium, provided the original author and source are credited. 